Supplement of

\title{
Atmospheric evolution of emissions from a boreal forest fire: the formation of highly functionalized oxygen-, nitrogen-, and sulfur-containing organic compounds
}

Jenna C. Ditto et al.

Correspondence to: Drew R. Gentner (drew.gentner@yale.edu)

The copyright of individual parts of the supplement might differ from the CC BY 4.0 License. 


\section{$\underline{\text { S1. Supporting sample collection details }}$}

The gas- and particle-phase samples discussed here were collected alongside a variety of other measurements including trace gas mixing ratios (e.g. $\mathrm{NO}_{\mathrm{x}}, \mathrm{O}_{3}, \mathrm{CO}, \mathrm{CO}_{2}, \mathrm{CH}_{4}, \mathrm{NH}_{3}$ ), black carbon concentrations, and gas- and particle-phase chemical characterization via online mass spectrometry. Carbon monoxide mixing ratios, select gas-phase tracer mixing ratios from PTRToF-MS, and AMS organic aerosol (OA) concentrations were used as supporting data in this study.

Carbon monoxide mixing ratios were measured with a Picarro G2401 analyzer every 2 seconds during the flights. When absolute ion abundances from adsorbent tube or filter data were used to discuss in-plume chemical transformations, abundances were normalized by the total carbon monoxide mass observed during the corresponding sampling period.

A proton transfer reaction time-of-flight mass spectrometer (PTR-ToF-MS, Ionicon Analytik $\mathrm{GmbH}$ ) was installed on the aircraft and collected measurements of volatile organic compounds (VOCs) with a time resolution of 1 second during the flights. The PTR-ToF-MS used a proton transfer reaction with $\mathrm{H}_{3} \mathrm{O}^{+}$as the primary reagent ion. VOCs were separated according to their mass to charge $(\mathrm{m} / \mathrm{z})$ ratio and detected using a high-resolution time-of-flight mass spectrometer. The data were processed using the TOFWARE software (Tofwerk AG). Additional details on these methods can be found in past work (Li et al., 2017).

A high-resolution aerosol mass spectrometer (AMS, Aerodyne Inc.) was used to measure mass concentrations of aerosol-phase organics, $\mathrm{NO}_{3}, \mathrm{SO}_{4}$ and $\mathrm{NH}_{4}$ (only organics are discussed here). Using an aerodynamic lens, particles were sampled into a region of low vacuum where they impacted a heated surface $\left(600^{\circ} \mathrm{C}\right)$, were vaporized, and then ionized by $70 \mathrm{eV}$ impaction. Ions were detected with a time-of-flight mass spectrometer. The AMS was operated in V mode 
with 10 second time resolution. A collection efficiency of 0.5 was determined using the method from Middlebrook et al. (Middlebrook et al., 2012), and applied to the data. The collection efficiency was also estimated by comparing the total mass concentrations with those derived from the UHSAS onboard the aircraft (ultra-high sensitivity aerosol spectrometer). UHSAS volume concentrations were converted to mass concentrations using densities weighted by the AMS components. Both methods yielded similar results.

S1.1. Adsorbent tubes: Combined gas- and particle-phase samples were collected on adsorbent tubes using a novel wing pod sampler (Figure S2) and integrated across a set of low and high altitudes in screens 1-4 (Figure S1, Table S1). The wing pod (a standard PMS canister) contained multiple adsorbent tubes, selection valves, a flow meter, a pump, and control and data acquisition electronics. The wing pod sample inlet consisted of a 7" long Teflon tube (1/8" diameter), connected to an inlet manifold for distribution to multiple installed adsorbent tubes (Figure S2). The small length of Teflon inlet tubing and manifold were designed as the only upstream components to have potential contact with the air sample before it entered the adsorbent tubes (residence time $\sim 0.3$ seconds). The inlet manifold was heated to slightly above ambient temperature, with temperature monitored by the control software. Solenoid valves were positioned downstream from each adsorbent tube to remotely switch the air flow through any one single tube at a time. Air was drawn through the selected tube by a small DC pump with an orifice and mass flow meter (Alicat Scientific) regulating and monitoring flow. A temperature/pressure sensor was attached on the inlet manifold for monitoring the thermophysical properties of sampled air. All flows, valve positions, temperatures, and pressures were recorded using a data acquisition board (LabJack T7) integrated into the pod.

Communications with the pod were performed via the aircraft's internal Ethernet network using 
custom LabVIEW software. This remote access allowed sampling to be triggered by an operator in flight, while minimizing the amount of sample inlet needed to supply ambient air to the adsorbent tubes.

The total adsorbent tube sampling times ranged from 4-52 minutes (depending on the time required to complete a set of transects) at an average flow rate of $285 \mathrm{sccm}$, yielding a total sample volume of $\sim 1-15 \mathrm{~L}$. These sampling times and flow rates were similar to those tested extensively in past work with the same adsorbent tubes (e.g. 6-25 L at 125-250 sccm (Sheu et al., 2018)), though the slightly higher flow rate in our study was verified to confirm minimal analyte breakthrough. VOCs from a mixture of $\mathrm{C}_{6}-\mathrm{C}_{13}$ species were used (hydrocarbons and functionalized species from a multicomponent gas cylinder mixture (Apel-Riemer)), consistent with past breakthrough testing with the same adsorbent tubes (Sheu et al., 2018). Our results showed good retention when adsorbent tubes were tested at $300 \mathrm{sccm}$ for 15 up to 60 minutes ( $7 \%$ loss on average), with some loss of $\mathrm{C}_{6}-\mathrm{C}_{9}$ compounds at longer sampling times (13\% loss on average). Therefore, this study was focused on hydrocarbons and functionalized species $\mathrm{C}_{10}$ and larger, to ensure that compounds had similar or lower volatility than the breakthrough test analyte sets, and thus similar or greater retention in the adsorbent tubes during field sampling.

To correct for any background contamination in subsequent data analyses, field blank adsorbent tubes were collected throughout the campaign by installing adsorbent tubes in the wing pod sampler during flight without sampling on them. All adsorbent tubes were spiked with a deuterated standard (containing n-hexadecane-d34, diethyl phthalate-d4, benz(a)anthracened12, n-octane-d18, ethylbenzene-d10, octanoic acid-d15, benzene-d6, and n-dodecanol-d25), and stored with 1/4" brass Swagelok caps in a $-30^{\circ} \mathrm{C}$ freezer before analysis. 
S1.2. Filters: Particles were sampled through a forward-facing isokinetic diffuser inlet (DMT) mounted on the roof of the aircraft. Particles with diameters approximately $<2.5 \mu \mathrm{m}$ were expected to be transmitted through this sampling setup based on transmission efficiency calculations using inlet dimensions and volume flow rates. Particles were collected onto PTFE filters using a multi-filter holder assembly mounted in the cabin of the aircraft. Filter sampling times ranged from 29-101 minutes, at an average flow rate of $46 \mathrm{~L} / \mathrm{min}$. One filter sample was collected per screen for screens 1-5 (Figure S1, Table S1).

Similar to adsorbent tube methods, filter field blanks were collected throughout the campaign by installing filters in the sampler with no air flow. Filters were spiked with the same deuterated standard discussed above, and stored in closed sterile petri dishes in a $-30^{\circ} \mathrm{C}$ freezer before analysis.

\section{$\underline{\text { S2. Supporting analytical methods details }}$}

S2.1. Adsorbent tubes: Adsorbent tubes were run on a GERSTEL Thermal Desorber TD $3.5+$, with a 6 minute dry purge at $100 \mathrm{~mL} / \mathrm{min}$ helium flow at $35^{\circ} \mathrm{C}$ to eliminate excess water trapped on the tubes, followed by a 10 minute desorption at $310^{\circ} \mathrm{C}$ to trap desorbed analytes in the GERSTEL Cooled Injection System (CIS) at $-100^{\circ} \mathrm{C}$. Tubes were spiked with a range of standards (the multicomponent gas cylinder mixture discussed above, in addition to a set of functionalized liquid standards with a range of oxygen-, nitrogen-, and sulfur-containing functional groups from Sigma Aldrich and AccuStandard (Ditto et al., 2018, 2020)) to evaluate possible losses associated with dry purging. While some losses of higher volatility compounds were observed as expected (Ochiai et al., 2014), analytes generally showed good retention ( $\sim 86 \%$ retained on average) during this preparatory step (Figure S4). CIS contents were 
subsequently desorbed at $325^{\circ} \mathrm{C}$ onto a DB5-MS-UI GC column $(30 \mathrm{~m}$ x $320 \mu \mathrm{m} \times 0.25 \mu \mathrm{m})$.

The column was held at $35^{\circ} \mathrm{C}$ for 5 minutes, followed by a $10^{\circ} \mathrm{C} /$ minute ramp to $325^{\circ} \mathrm{C}$, and a 3 minute hold at $325^{\circ} \mathrm{C}$. Helium carrier gas flowed through the column at $1.5 \mathrm{~mL} / \mathrm{min}$. The APCI source was operated in positive mode and the Q-TOF was operated in MS mode, following methods in past work (Khare et al., 2019).

Daily system check standards were run with adsorbent tube samples, including diluted diesel fuel (\#2 diesel fuel from AccuStandard, DRO-AK-102-LCS-10X-R1) to confirm calibration and transmission of a complex hydrocarbon mixture through the analytical system, along with a mixture of hydrocarbons and functionalized species from the multicomponent gas cylinder mixture discussed above (Sheu et al., 2018). NIST Reference Gulf of Mexico 2779 Macondo Crude Oil was also run for response factor mass calibrations across the analyte range of interest, discussed in Section S3 (Khare et al., 2019).

S2.2 Filters: Filters were extracted in methanol with 60 minutes of sonication, and solvent was evaporated down to $200 \mu \mathrm{L}$ under gentle $\mathrm{N}_{2}$ flow (Ditto et al., 2018). Next, $5 \mu \mathrm{L}$ aliquots were analyzed on an SBAQ reverse phase column using water (A) and methanol (B) as mobile phases, running the following solvent gradient: $95 \%$ (A) for 2 minutes, then solvents ramped to $10 \% \mathrm{~A}$ and $90 \% \mathrm{~B}$ for 20 minutes, then held at $10 \% \mathrm{~A}$ and $90 \% \mathrm{~B}$ for 5 minutes, and finally returned to initial conditions for the next run (Ditto et al., 2018). The ESI source was operated in positive and negative ionization mode, and the Q-TOF was operated in both MS and MS/MS mode, following previously described methods (Ditto et al., 2018, 2020). All data discussed here report both positive and negative mode peaks; when a compound ionized well in both modes, its abundances in positive and negative mode were averaged, and it was only tabulated once. 
Filter extracts were also analyzed via GC-APCI-MS using the GERSTEL TD 3.5+. For GC-APCI-MS analysis, $1 \mu \mathrm{L}$ aliquots were automatically injected by the GERSTEL system into the TD inlet. The inlet was subsequently desorbed at $310^{\circ} \mathrm{C}$ for 10 minutes, while trapping analytes on the CIS at $-100^{\circ} \mathrm{C}$, as described above. The APCI and Q-TOF operating conditions were the same as for adsorbent tubes.

Daily system checks using authentic standards were run with filter samples on LC and GC, focusing on a set of functionalized liquid standards with a range of oxygen-, nitrogen-, and sulfur-containing functional groups (discussed above). These standards were used to determine an average response factor of functionalized analytes, which was in turn used to estimate mass concentration analyzed with the filter samples (Section S4).

In addition, as part of data quality control for both adsorbent tubes and filters, we performed a targeted search through sample data for common biomass burning tracers such as levoglucosan, benzenediols, methoxyphenols, vanillin, vanillic acid, acetovanillone, and dehydroabietic acid, among others. However, the goal of this study was to examine the complex mixture in forest fire smoke and to study molecular-level trends in the evolution of the mixture as a whole. As such, the methods applied here for sample analysis and data analysis were geared towards this purpose, rather than to focus on particular tracer compounds, which were targeted by other instruments in the aircraft payload (e.g. PTR-ToF-MS). While several of these tracers were outside of the carbon number range of interest in this study, we searched for them in the adsorbent tube and filter data to ensure that our methods captured a range of expected biomass burning emissions and transformation products based on past field and laboratory observations (e.g. levoglucosan was observed in the particle phase across all 5 screens; vanillin and 
acetovanillone were observed in all 4 screens of gas-phase measurements; vanillic acid was observed prominently in both phases (Schauer et al., 2001; Simoneit et al., 1993)).

\section{$\underline{\text { S3. Supporting data analysis methods details }}$}

There are two types of analyses discussed in this work: non-targeted (primarily for particle-phase LC-ESI-MS, LC-ESI-MS/MS, and GC-APCI-MS) and targeted (primarily for gasphase GC-APCI-MS). The details of both approaches are discussed in previous work, but we summarize the important points here.

S3.1 Non-targeted analysis and QA/QC for particle-phase samples: In brief, for nontargeted analysis, the Q-TOF examined mass spectra across the entire LC elution time for a particular sample. Peak, formula, and structural identifications were extensively quality controlled (including subtraction of any contaminants or artifacts from field blanks, and elimination of low quality peaks and formula/structural identifications (Ditto et al., 2018, 2020)) but were not restricted to target a particular set of compounds. Elemental formula parameters were set to $\mathrm{C}_{3-60} \mathrm{H}_{4-122} \mathrm{O}_{0-20} \mathrm{~N}_{0-3} \mathrm{~S}_{0-1}$, and no significant change in top-ranked identifications was observed when expanding the nitrogen and sulfur elemental counts. For LC-ESI-MS/MS analysis, mass spectra were imported to SIRIUS with CSI:FingerID, and this software was used to predict structures. We note that in this study, we did not focus on exact molecular configurations but rather the presence or absence of functional groups, similar to past work (Ditto et al., 2020). We also note that organonitrates were tallied according to prior approaches; this functional group was poorly identified by SIRIUS and CSI:FingerID, so characteristic neutral losses were used to identify organonitrates (see reference for further discussion (Ditto et al., 2020)). However, as a result, the co-occurring functional groups on organonitrate compounds 
(predicted by SIRIUS and CSI:FingerID) were assumed to be invalid. So, organonitrates were included in the functional group tally shown in Figure 1C and Figure S6, but not in any subsequent analyses of functional group co-occurrence. The effect of this exclusion was minor since organonitrates had minimal presence in the particle phase in this relatively fresh forest fire plume ( $\sim 3 \%$ on average; Figure $1 \mathrm{C})$. In addition, nitrogen or sulfur atoms in non-aromatic rings were tallied both as a "nitrogen in ring" or "sulfur in ring" (Figure 1C) and as any other applicable functional group (e.g. amine, sulfone). Hence, they are reported separately as structural features throughout the manuscript (e.g. Figure 1C, Figure S6-S7A). Importantly, we note that none of the sulfide-containing compounds identified in this work were present as ringbound sulfur.

S3.2. Targeted analysis and QA/QC for gas-phase samples: For targeted analysis, we searched for specific large sets of molecular ions across $\mathrm{C}_{10}-\mathrm{C}_{25}$ with double bond equivalents (DBE) or corresponding degrees of unsaturation from 0-15 for $\mathrm{C}_{x} \mathrm{H}_{y}, \mathrm{C}_{\mathrm{x}} \mathrm{H}_{y} \mathrm{O}_{1}, \mathrm{C}_{\mathrm{x}} \mathrm{H}_{\mathrm{y}} \mathrm{S}_{1}$, and $\mathrm{C}_{\mathrm{x}} \mathrm{H}_{\mathrm{y}} \mathrm{N}_{1}$ compound classes. While some compounds with a greater heteroatom count could be present in the adsorbent tube (i.e. gas-phase) samples, heteroatom counts were limited to one for each compound class to facilitate the targeted ion search. We focused on this carbon number range to supplement other on-board instrumentation measuring VOCs (i.e. PTR-ToF-MS) and also because the adsorbent tubes' sampling and analytical conditions were optimized for this range of molecular weights.

Peaks for each ion were extracted at $10 \mathrm{ppm}$ mass tolerance and integrated with custom Igor Pro code. Samples were all blank subtracted (using field blanks), and known contaminants and artifacts were removed. Peak areas for $\mathrm{C}_{\mathrm{x}} \mathrm{H}_{\mathrm{y}}$ ions were converted to mass using a $\mathrm{C}_{\mathrm{x}} \mathrm{H}_{\mathrm{y}}$ response factor for individual carbon numbers and DBEs, determined based on the known 
distribution of carbon numbers and DBEs in the NIST Gulf of Mexico 2779 Macondo Crude Oil standard with GC and soft ionization (Khare et al., 2019; Worton et al., 2015). To convert $\mathrm{C}_{\mathrm{x}} \mathrm{H}_{\mathrm{y}} \mathrm{O}_{1}$ and $\mathrm{C}_{\mathrm{x}} \mathrm{H}_{\mathrm{y}} \mathrm{S}_{1}$ peak areas to mass, we applied the average $\mathrm{C}_{\mathrm{x}} \mathrm{H}_{\mathrm{y}}$ response factors for aromatic compounds (which had limited fragmentation in the APCI source) based on an intercomparison of mass responses from available oxygen- and sulfur-containing individual authentic standards, evaluations of fragmentation patterns of these functionalized species, and determination of an analogous carbon number based on the volatility difference introduced by adding an oxygen or sulfur heteroatom to $\mathrm{C}_{\mathrm{x}} \mathrm{H}_{\mathrm{y}}$ hydrocarbon, as discussed in past work (Khare et al., 2020). This resulted in shifting the average response factors up by 1 or 2 carbon numbers when accounting for the presence of oxygen or sulfur heteroatoms, respectively, and accounting for the ratio of $[\mathrm{M}+\mathrm{H}]^{+}$to $[\mathrm{M}]^{+}$ion abundance observed. $\mathrm{C}_{\mathrm{x}} \mathrm{H}_{\mathrm{y}} \mathrm{O}_{1}$ and $\mathrm{C}_{\mathrm{x}} \mathrm{H}_{\mathrm{y}} \mathrm{S}_{1}$ response factors were based on the $\mathrm{C}_{\mathrm{x}} \mathrm{H}_{\mathrm{y}}$ response factor because of limited availability of individual oxygen- or sulfur-containing standards across the entire carbon number and structural range, and because of greater structural ambiguity in these complex functionalized mixtures (due to a range of possible oxygen- and sulfur-containing functional groups and the possibility of double bonds both in the carbon backbone structure and in the functional group itself). We acknowledge that this approach comes with added uncertainty and apply it here to provide useful context for the relative mass of $\mathrm{C}_{\mathrm{x}} \mathrm{H}_{\mathrm{y}} \mathrm{O}_{1}$ and $\mathrm{C}_{\mathrm{x}} \mathrm{H}_{\mathrm{y}} \mathrm{S}_{1}$ compared to $\mathrm{C}_{\mathrm{x}} \mathrm{H}_{\mathrm{y}}$. However, it is critical to note that the uncertainty in the conversion from peak area to mass does not affect our results that describe trends across screens and the diversity of molecular size and structure observed (e.g. straight/branched vs. aromatic)these features were all observed in the ion abundance data prior to mass estimation. $\mathrm{C}_{\mathrm{x}} \mathrm{H}_{\mathrm{y}} \mathrm{N}_{1}$ was studied here in terms of peak area only. 
The vast majority of the total compound mass observed via targeted analysis of adsorbent tube samples in the $\mathrm{C}_{10}-\mathrm{C}_{25}$ range should have existed in the gas phase. This is based in part on significant undersampling for particles at the adsorbent tube inlet (discussed in the main text). This is also based on partitioning coefficients calculated with estimated aerosol loading (from AMS OA concentration data, Figure 4B) and the approximate saturation mass concentration for this carbon number range (Equation 1, from Donahue et al., 2009) (Donahue et al., 2009, 2011):

$$
\xi_{i}=\frac{1}{1+\frac{C_{i}^{*}}{C_{O A}}}
$$

In Equation $1, \xi_{i}$ is a partitioning coefficient of compound $i, C_{i}^{*}$ is the effective saturation concentration of compound $i$, and $C_{O A}$ is the mass concentration of the existing organic particle phase. As shown in Table S2, compounds below $\sim \mathrm{C}_{22}-\mathrm{C}_{23}$ should have existed mostly in the gas phase, though compounds $\sim \mathrm{C}_{20}$ and up would have readily partitioned from and equilibrated with the particle phase with small changes in OA concentration. This range of observed compounds therefore had likely contributions from semivolatile particle-phase species evaporating with plume dilution, as discussed in the main text in Section 3.3 and Figure 4B.

\section{$\underline{\text { S4. Representativeness of mass analyzed via filter and adsorbent tube samples }}$}

The analysis of particle-phase samples discussed here used methods geared towards functionalized OA, i.e. OA with one or more oxygen-, nitrogen-, and/or sulfur-containing functional groups or structural features. Samples were extracted in methanol due to its effectiveness at extracting polar analytes from similar filter media in past studies (Ditto et al., 2018; Ng et al., 2008; Riva et al., 2016a, 2016b; Seinfeld et al., 2008); no distinct trends were observed that suggested major differences in extraction efficiency among heteroatom-containing compounds. 
Samples were analyzed using electrospray ionization (ESI), which is sensitive towards compounds with oxygen-, nitrogen-, and/or sulfur-containing functional groups that readily interact with protons and other ions in the mobile phase solvents to form charged adducts. For particle-phase samples analyzed with LC-ESI-MS, CH and CHS compound classes were not measured, as they ionized poorly in the ESI source (Ditto et al., 2018, 2019). For these same particle-phase samples analyzed via GC-APCI-MS, $\mathrm{CH}$ and $\mathrm{CHS}$ were measured (due to improved ionization via $\mathrm{APCI}$ ), but the contribution of $\mathrm{CH}$ was likely underestimated due to fragmentation of alkanes in the ionization source (discussed in Figure S5 and explicitly calibrated for in the targeted adsorbent tube analysis focused on gas-phase compounds (Khare et al., 2019)) and due to possible $\mathrm{CH} / \mathrm{CHS}$ solubility limitations in the methanol extraction solvent. Though not designed to be an exact intercomparison for mass closure, we evaluated the total mass analyzed from the filters (via LC-ESI, since these results are the ones primarily displayed and discussed throughout the manuscript) and adsorbent tubes (via GC-APCI) in this study. The sample preparation and analysis methods for filters were tailored for the analysis of functionalized OA; an estimate of functionalized compound mass loading from non-targeted LCESI-MS analysis of filter samples with average ESI response factors (Ditto et al., 2018) suggested that these functionalized components represented an average of $26 \pm 6 \mu \mathrm{g} / \mathrm{m}^{3}$ across screens 1-4. For comparison, the average AMS OA mass concentration across these same filter sampling times was $31 \pm 5 \mu \mathrm{g} / \mathrm{m}^{3}$. However, there is evidence in this and in past studies for an important contribution from non-functionalized biomass burning $\mathrm{OA}$ (i.e. $\mathrm{CH}$ compounds) (Corrigan et al., 2013; Zhou et al., 2017), which would not be measured by the filter sampling methods discussed here. This suggests that these LC-ESI and AMS methods may have measured some overlapping but some differing subsets of OA mass. For comparison, adsorbent tube 
samples contained $21 \pm 6 \mu \mathrm{g} / \mathrm{m}^{3}$ of gas-phase $\mathrm{C}_{\mathrm{x}} \mathrm{H}_{\mathrm{y}}, \mathrm{C}_{\mathrm{x}} \mathrm{H}_{\mathrm{y}} \mathrm{O}_{1}$, and $\mathrm{C}_{\mathrm{x}} \mathrm{H}_{\mathrm{y}} \mathrm{S}_{1}$ compounds, from targeted search results in the $\mathrm{C}_{10}-\mathrm{C}_{25}$ range.

In LC-ESI-MS, we have observed response factors for individual standards to vary across complex mixtures with evident but uncertain relationships to compound classes and functional groups, resulting in sensitivity differences between compounds in the ESI source. In this and in past work, we compared compounds across these diverse multi-functional mixtures by both occurrence and abundance. For the latter, it was necessary to assume an equal ionization efficiency across all compounds (and thus an identical average response factor) because of the challenges associated with assigning compound-specific ionization efficiencies to hundreds of multifunctional compounds in a complex mixture without sufficient reference standards (Ditto et al., 2020). Thus, for comparison, we showed results tabulated both by occurrence and by abundance where applicable (e.g. Figure S5, S6, S8, S9). Results tabulated by occurrence were otherwise not used in any of the analyses discussed here, and were provided as supporting data to aid in the interpretation of results.

\section{$\underline{\text { S5. Differences in LC and GC results for particle-phase data }}$}

As mentioned in Materials and Methods, we observed compounds with different oxygen, nitrogen, and sulfur content in LC-ESI and GC-APCI measurements for particle-phase filter samples, resulting from differences in chromatographic and ionization approaches. LC is better suited for more polar compounds that are less volatile and contain more functional groups. In contrast, GC-amenable compounds tend to be less polar and more thermally stable, with overall less functionality. ESI is very sensitive towards functionalized species (e.g. that can be readily protonated or deprotonated), while APCI in the configuration used here can more effectively 
ionize less polar analytes (Kondyli and Schrader, 2019). For example, particle-phase compounds from filter samples observed via non-targeted LC-ESI analysis contained an overall average of 4.7 oxygen atoms, with $\overline{O / C}=0.4$. Nitrogen-containing compounds had an $\overline{O / N}=2.5$, and sulfur-containing compounds had an $\overline{O / S}=5.0$. In contrast, compounds from these same filter samples observed via non-targeted GC-APCI analysis contained an overall average of 2.1 oxygen atoms, with $\overline{O / C}=0.2$. Nitrogen-containing compounds had an $\overline{O / N}=1.8$, and sulfurcontaining compounds had an $\overline{O / S}=3.3$. An estimate of carbon oxidation state for $\mathrm{CH}$ and $\mathrm{CHO}$ compounds (Kroll et al., 2011) yielded $\overline{O S C}=-0.5$ for LC-ESI filter samples and a less oxidized $\overline{O S C}=-1.3$ for GC-APCI filter samples.

An analysis of filter extracts with non-targeted GC-APCI-MS (Figure S5) showed greater contributions of carbon-, hydrogen-, and oxygen-containing (CHO) and carbon- and hydrogencontaining $(\mathrm{CH})$ compound classes than non-targeted LC-ESI-MS because these compound classes are more GC-amenable, while LC-ESI-MS highlighted contributions from more functionalized species, along with $\mathrm{CHO}$ species. As the complex mixture of compounds in the forest fire plume aged, it became increasingly functionalized and likely less GC-amenable. Thus, using exclusively GC techniques to study the evolution of smoke plumes may miss more functionalized, non-GC amenable compounds. Here, we focused on LC-ESI-MS data for the particle phase to study these functionalized species. While LC-ESI-MS does not ionize CH and CHS compound classes effectively, these were outside the scope of our study. 




Figure S1. The flight path tracking the forest fire plume on June 25, 2018. Shaded blue regions represent local oil sands processing facilities. Cross hatching represents approximate location of the fire source, located $\sim 10 \mathrm{~km}$ from screen 1 (SP is the south plume, whose source was identified via satellite imagery; the north plume source was not identified via satellite imagery, so it is not explicitly shown here but was $\sim 8-19 \mathrm{~km}$ to the northeast of the SP at screen 1 and both plumes were estimated to be approximately the same age). Screens 1 and 2 were $\sim 26 \mathrm{~km}$ apart, screens 2 and 3 were $\sim 24 \mathrm{~km}$ apart, screens 3 and 4 were $\sim 29 \mathrm{~km}$ apart, and screens 4 and 5 were $\sim 83 \mathrm{~km}$ apart. Prevailing winds were from the southeast during the sampling period as shown by the wind rose in the upper right. Map used to plot flight tracks: (C) Google Earth: Google, Maxar Technologies. 


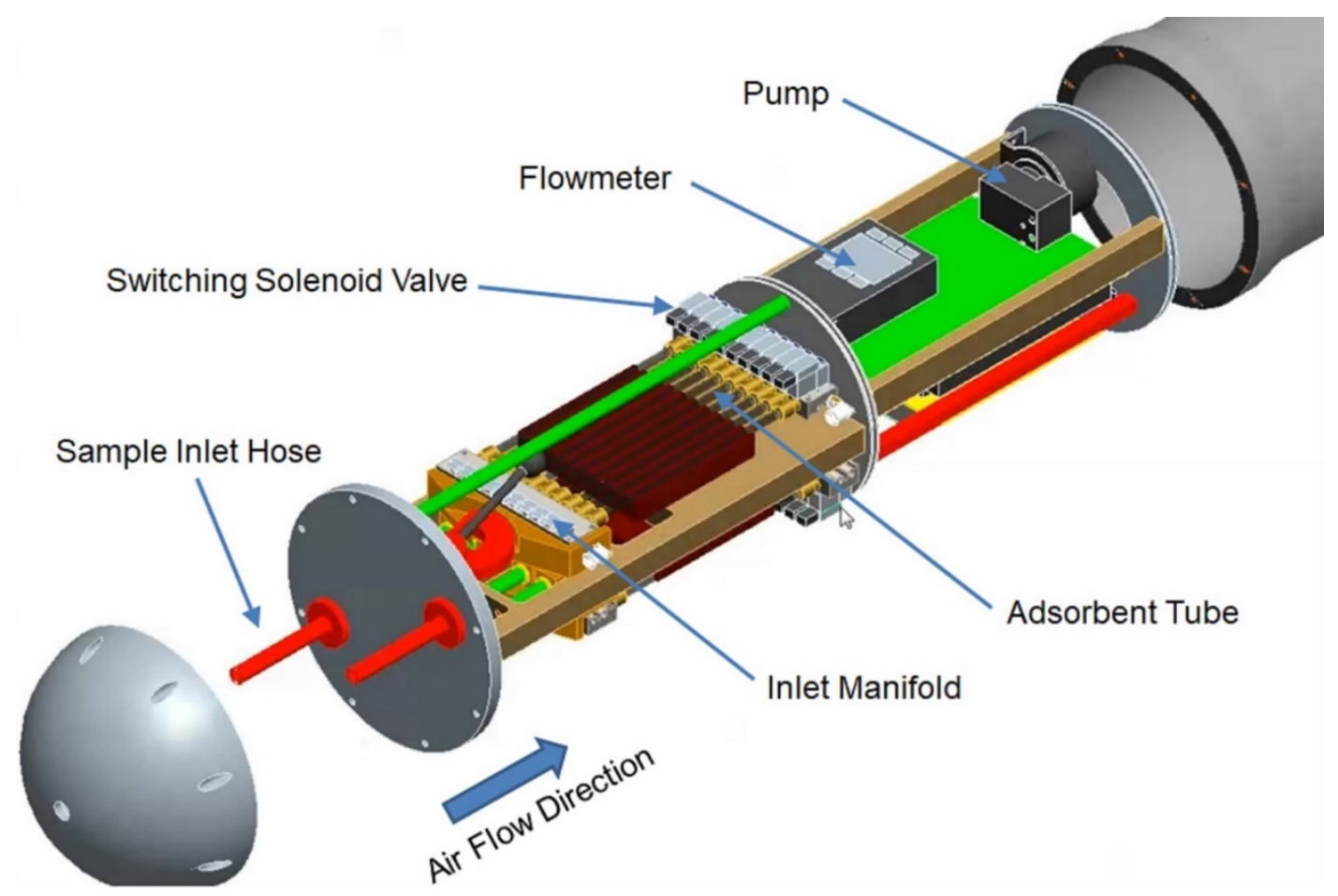

Figure S2. Drawing depicting the key components of the wing pod sampler. Teflon tubing (7" long, 1/8" diameter) was connected to the sample inlet hose and to the inlet manifold.

Temperature and pressure sensors were attached to the inlet manifold to monitor the properties of sampled air. Adsorbent tubes for the entire flight were loaded into the sampler, and each tube was connected to the manifold. A solenoid valve was positioned downstream of each adsorbent tube to remotely switch air flow between samples. A flow meter and pump were installed further downstream to control air flow. 



Figure S3. Summary of adsorbent tube and filter sample collection methods and data analysis. 


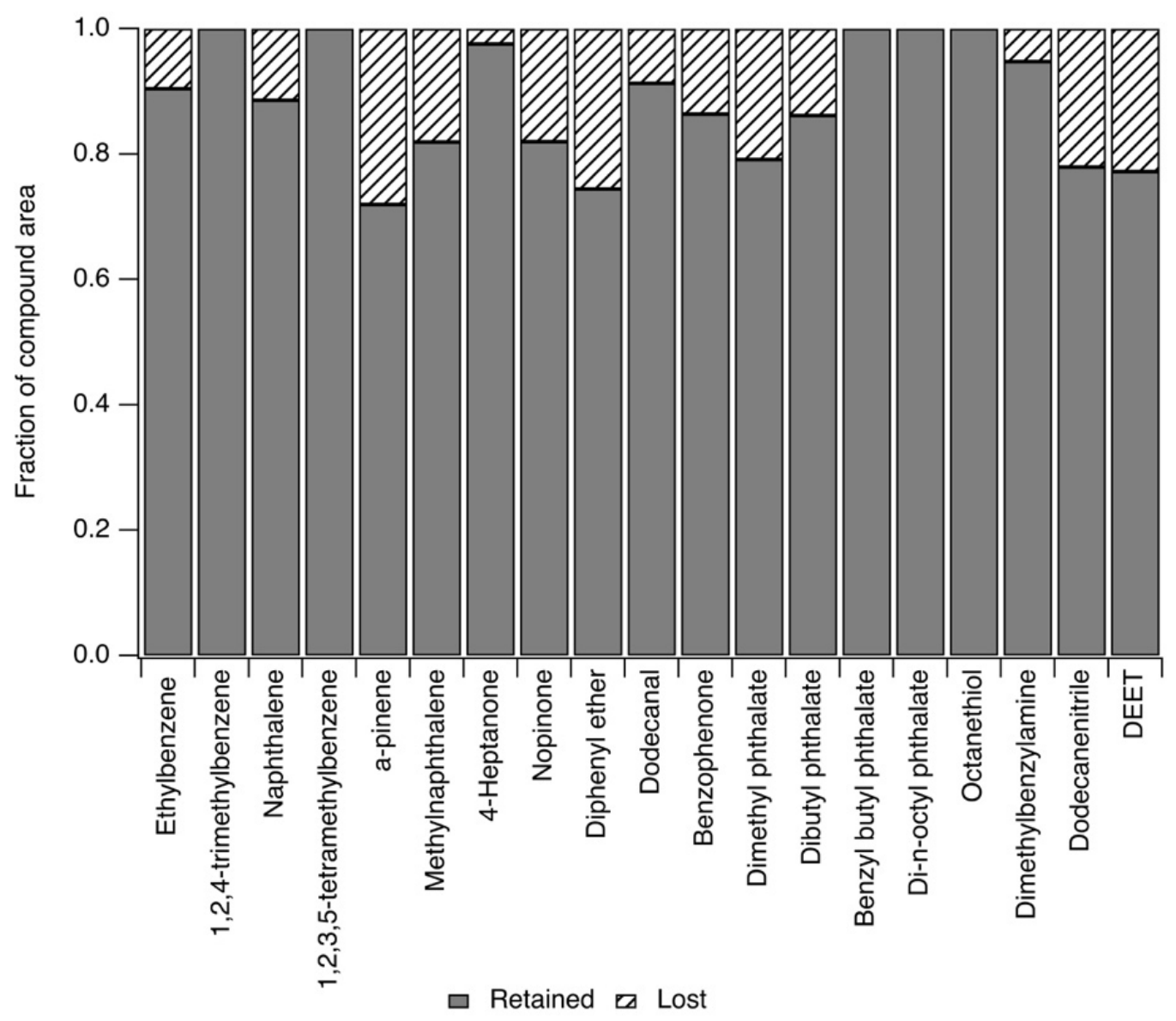

Figure S4. Evaluation of losses associated with adsorbent tube dry purge prior to tube desorption and analysis. Peak areas from experiments using standards with and without a dry purge were compared (y-axis). While some loss of volatile analytes is expected (Ochiai et al., 2014), most analytes across a range of functional groups were retained reasonably well ( $\sim 86 \%$ retained, on average). 
(A) Compound class, by abundance

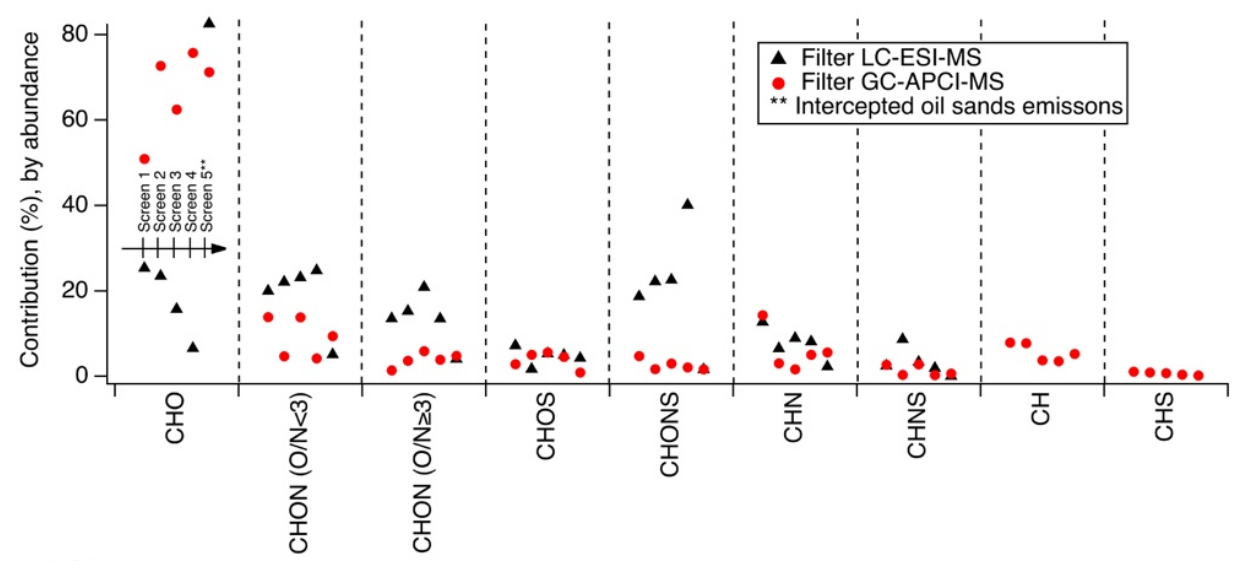

(B) Compound class, by occurrence

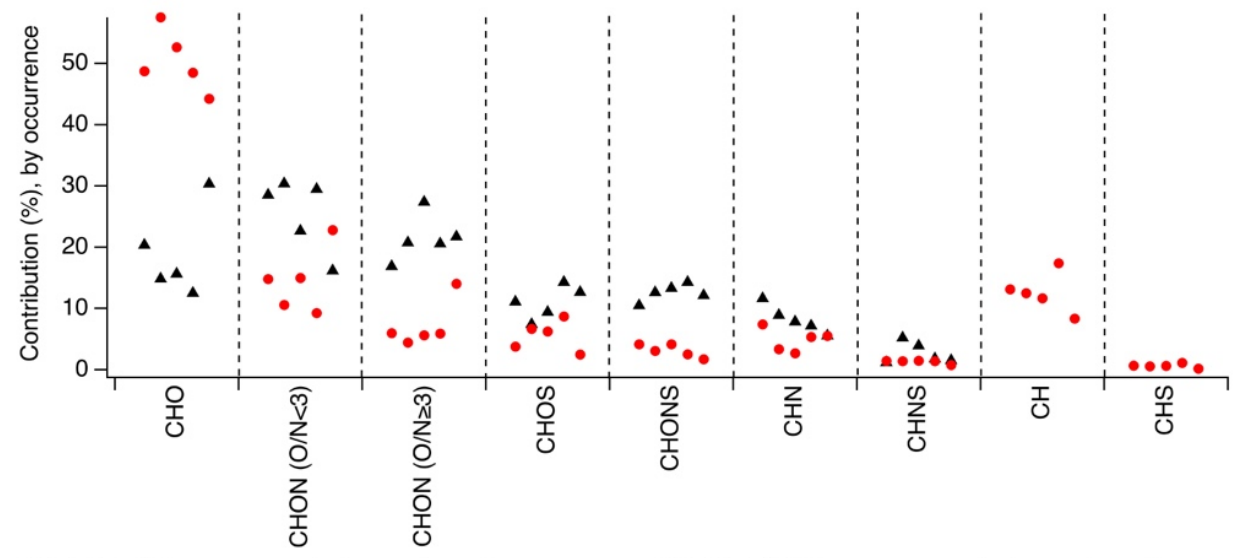

(C) LC-ESI compound class abundance

(D) GC-APCl compound class abundance
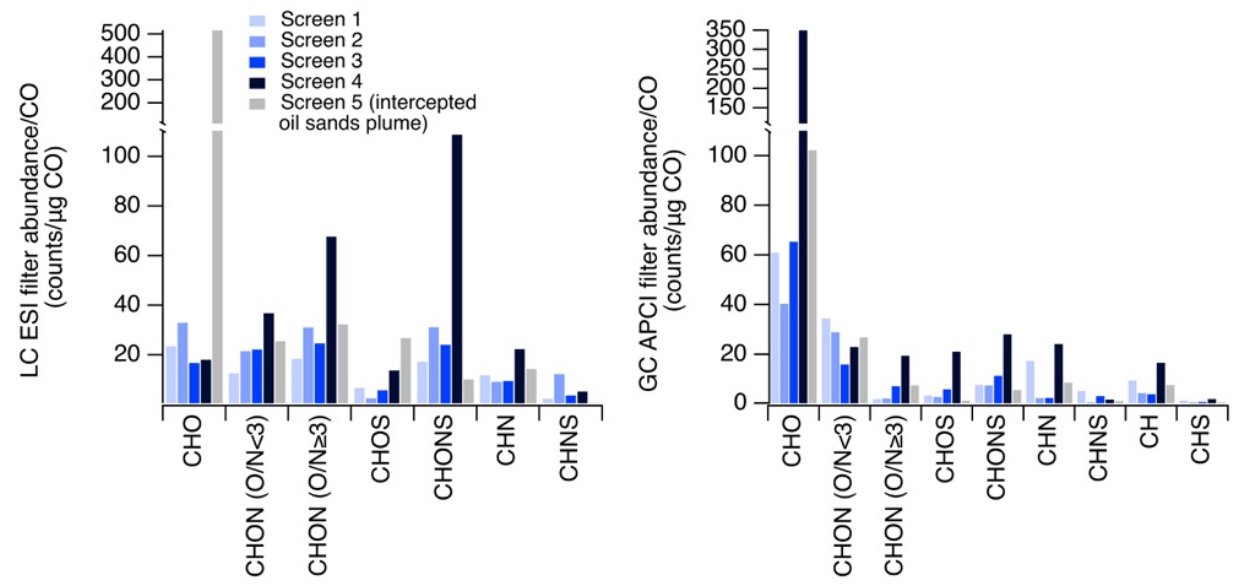

Figure S5. (A) Compound class distribution for particle-phase non-targeted LC-ESI-MS and GC-APCI-MS analyses, weighted by ion abundance. Percent contribution on the y-axis refers to each compound class' contribution to all observed compound ion abundance in LC or GC analysis. (B) For comparison, compound class distribution for particle-phase non-targeted LCESI-MS and GC-APCI-MS analyses, shown by occurrence (i.e. the number of compounds in each category - see Section S4 for further discussion). (C) Compound class distribution from particle-phase LC-ESI-MS analysis, and (D) compound class distribution from particle-phase 
GC-APCI-MS analysis, both shown as raw ion abundance normalized by the average carbon monoxide measurement corresponding to the filter sampling period. In all panels, $\mathrm{CH}$ and $\mathrm{CHS}$ compounds are excluded from LC-ESI-MS analysis due to poor ESI ionization efficiency (Section S5). CH in GC-APCI-MS analysis may be underestimated due to known fragmentation of alkanes in the APCI source. This fragmentation is accounted for in the mass calibrated, targeted analysis of adsorbent tube compounds. These data are shown to support Figure 1A-B. GC-APCI-MS data from filter extracts are shown here for comparison with LC-ESI-MS data, but are not used in subsequent analyses. Differences between GC and LC results are due to differences in ionization techniques used in both methods (see Section S5) as well as changes in mixture composition that shift its GC- and LC-amenability.

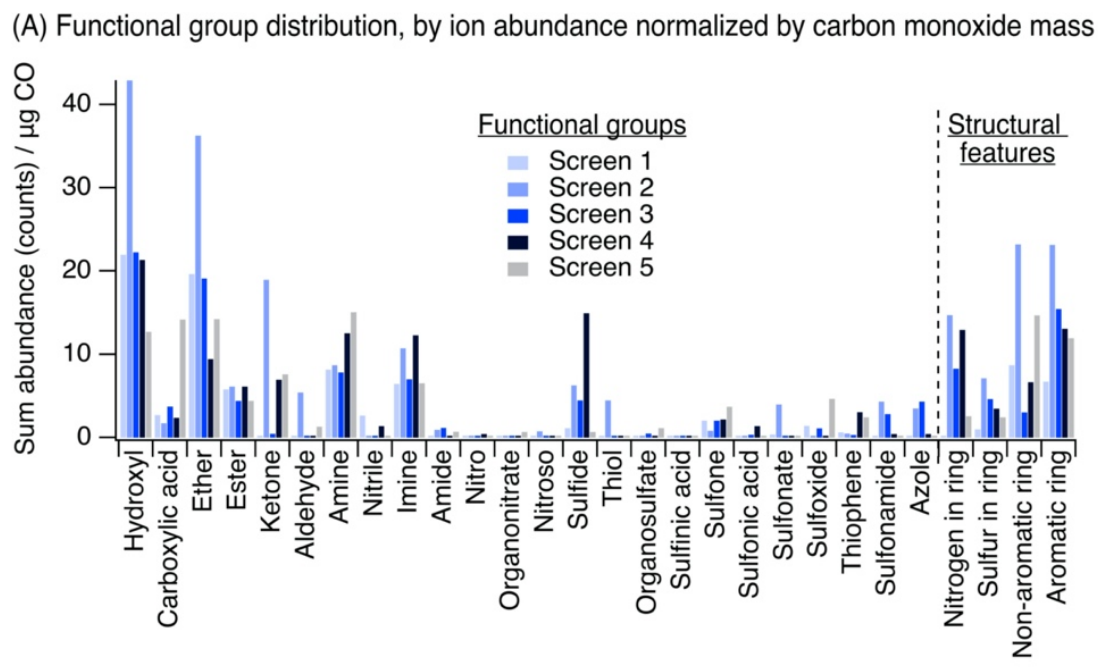

(B) Functional group distribution, by occurrence

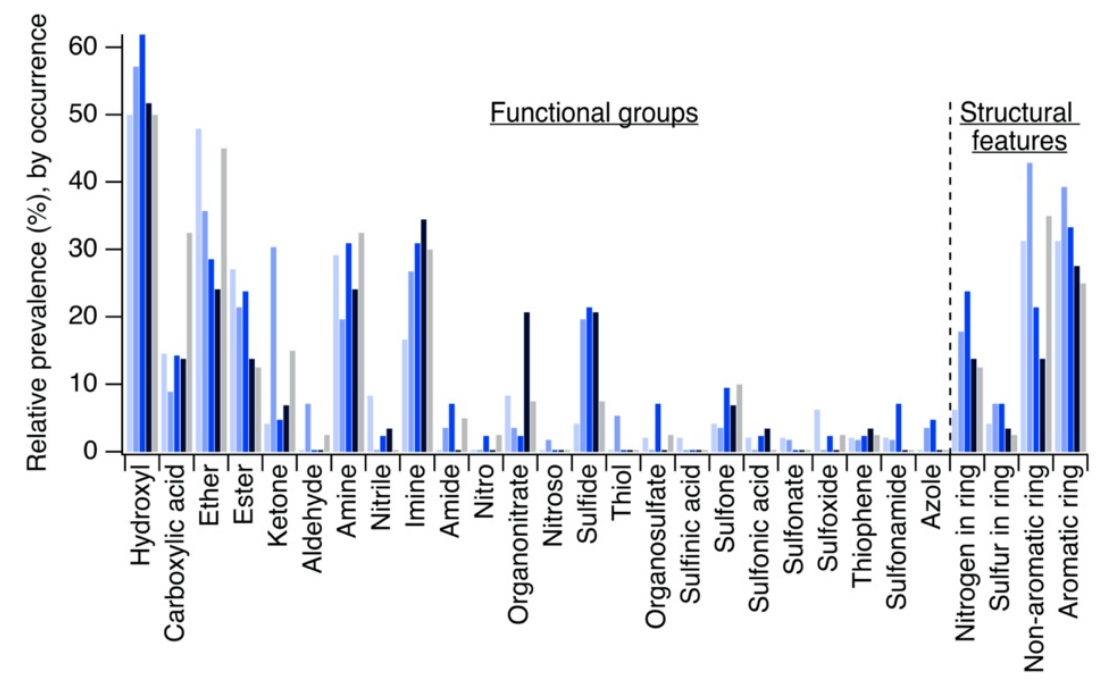

Figure S6. Functional group distribution of particle-phase functionalized OA from LC-ESIMS/MS analysis represented (A) by raw abundance (normalized by carbon monoxide mass from corresponding sampling time) and (B) by occurrence (i.e. not weighted by abundance, not normalized by carbon monoxide - see Section S4 for further discussion). These data are shown to support Figure 1C. 
(A) CHONS functional groups, by screen

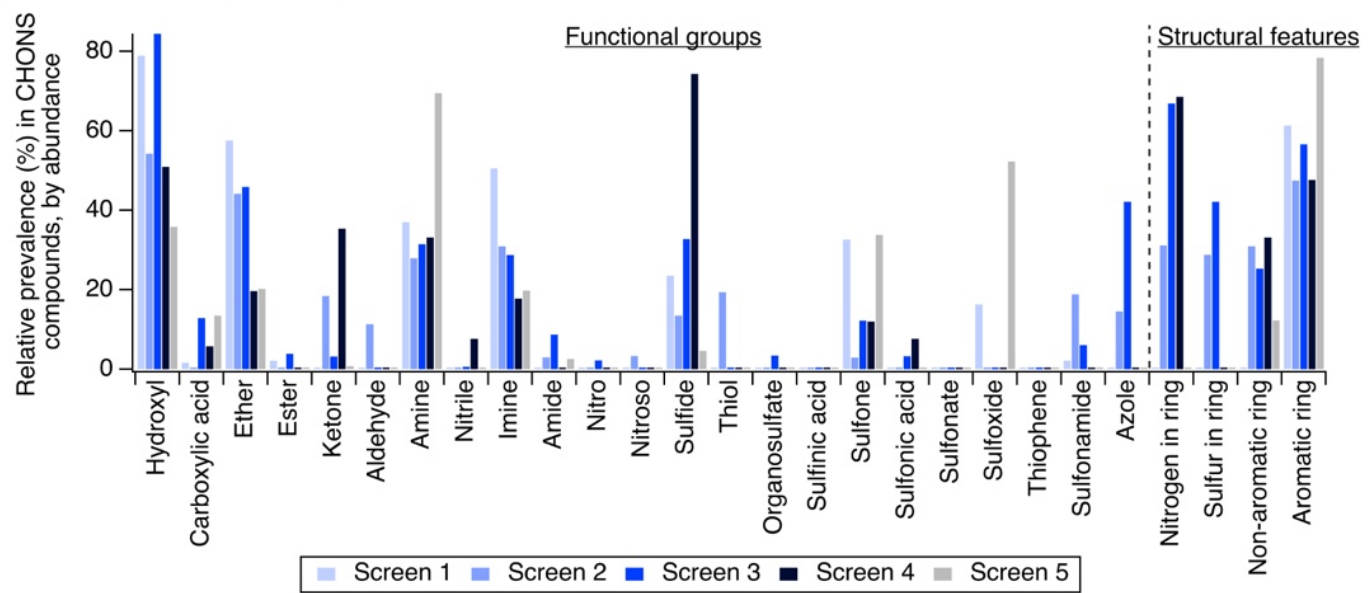

(B) Relationship between other $\mathrm{N}$-containing functional groups and $\mathrm{CHONS}$ contribution

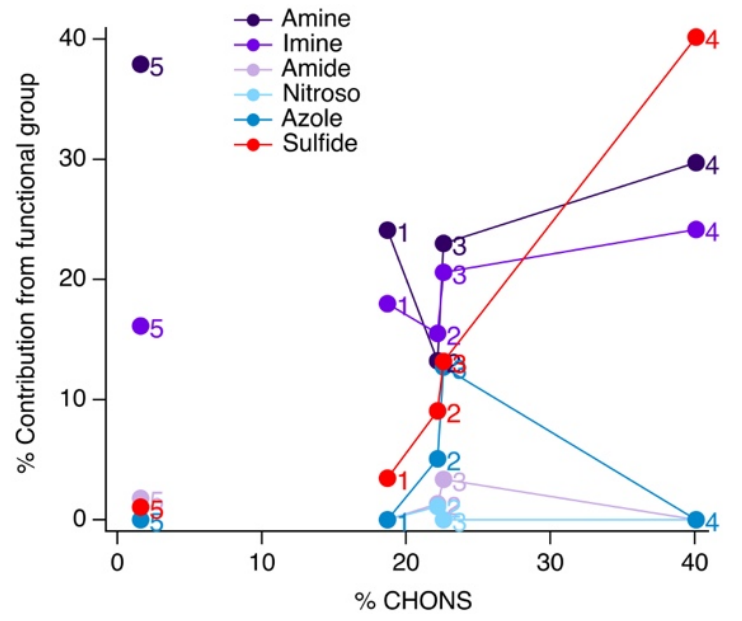

Figure S7. (A) Functional groups that contributed to CHONS compounds, weighted by abundance and shown by screen (shown to support Figure 2A-B). (B) Relationship between the contribution of amine, imine, amide, nitroso, azole, and sulfide groups to all functionalized OA and the contribution of the CHONS compound class prevalence. Numbers beside each marker represent screen number. 
(A) CHONS volatility distribution, by screen, by abundance

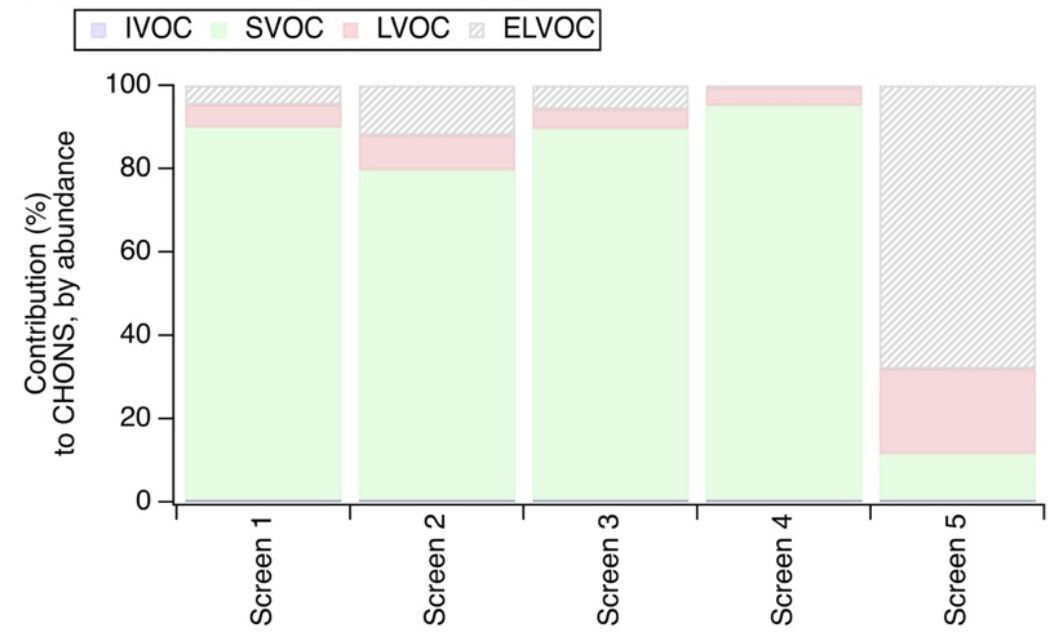

(B) CHONS volatility distribution, by screen, by occurrence

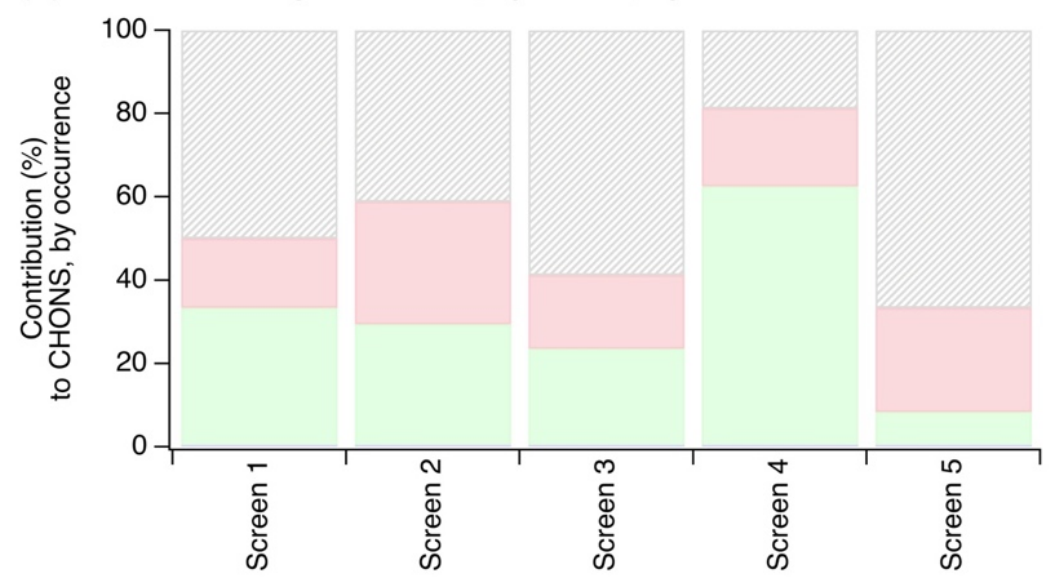

Figure S8. Volatility distribution of CHONS compounds, (A) shown by screen, weighted by abundance (to support Figure 2C), and (B) shown by occurrence (for comparison-see Section $\mathrm{S} 4$ for further discussion). Volatility was estimated using the parameterization in Li et al. (Li et al., 2016) and grouped into volatility bins following Li et al. and Donahue et al. (i.e. IVOC: 300 $<\mathrm{C}_{0}<3 \times 10^{6} \mu \mathrm{g} / \mathrm{m}^{3}$, SVOC: $0.3<\mathrm{C}_{0}<300 \mu \mathrm{g} / \mathrm{m}^{3}$, LVOC: $3 \times 10^{-4}<\mathrm{C}_{0}<0.3 \mu \mathrm{g} / \mathrm{m}^{3}$, ELVOC: $\mathrm{C}_{0}<10^{-4}$ (Donahue et al., 2011; Li et al., 2016)). 
(A) Volatility distribution, by abundance

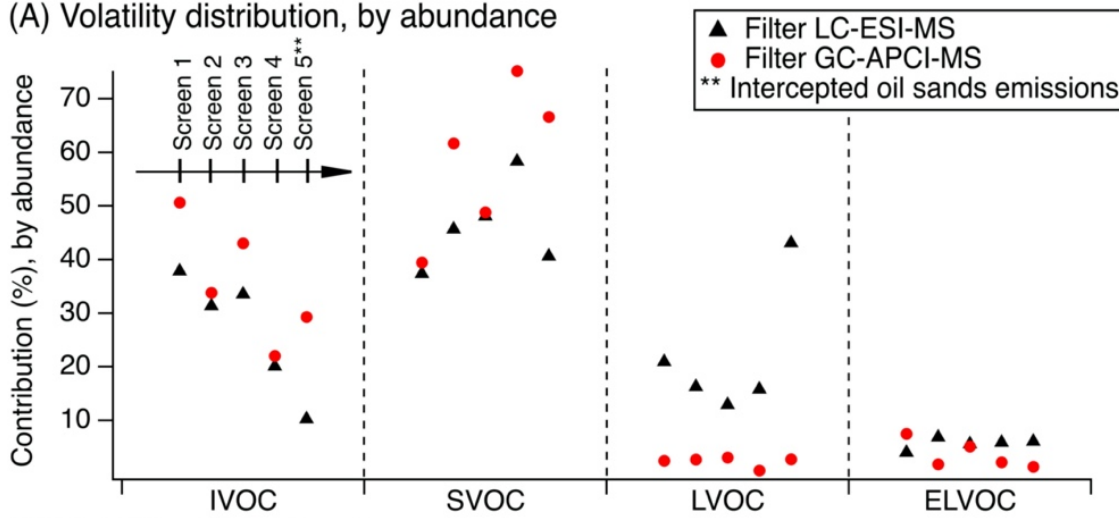

(B) Volatility distribution, by occurrence

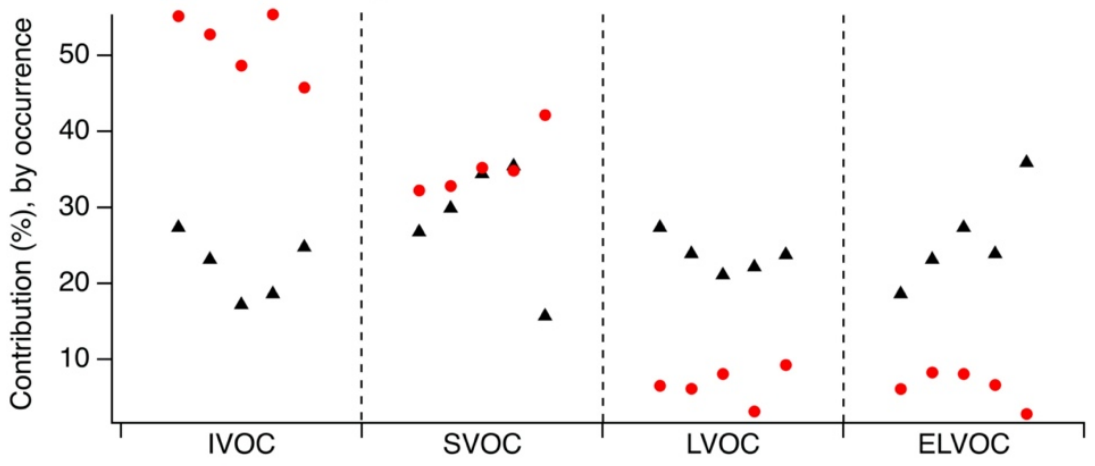

(C) LC-ESI filter volatility abundance

(D) GC-APCl filter volatility abundance
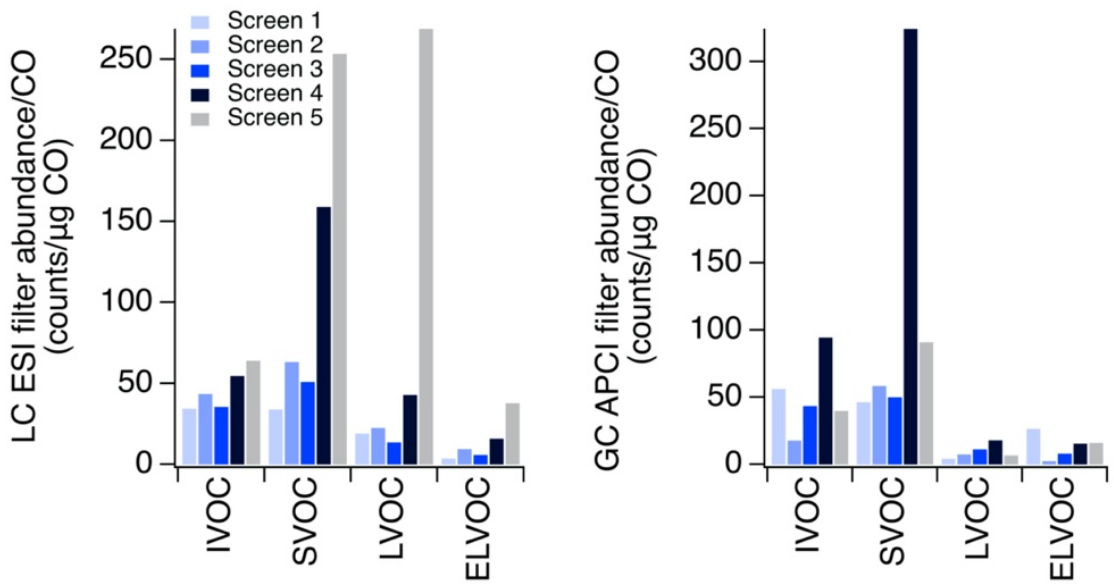

Figure S9. Volatility distribution of particle-phase compounds from non-targeted analysis, (A) weighted by abundance, (B) by occurrence (for comparison-see Section S4 for further discussion), (C) for particle-phase LC-ESI-MS samples, shown as raw abundance normalized by carbon monoxide, and (D) for particle-phase GC-APCI-MS samples, shown as raw abundance normalized by carbon monoxide. For (A-D), volatility was estimated using the parameterization in $\mathrm{Li}$ et al. and grouped into volatility bins following Li et al. and Donahue et al. (i.e. IVOC: 300 $<\mathrm{C}_{0}<3 \times 10^{6} \mu \mathrm{g} / \mathrm{m}^{3}$, SVOC: $0.3<\mathrm{C}_{0}<300 \mu \mathrm{g} / \mathrm{m}^{3}$, LVOC: $3 \times 10^{-4}<\mathrm{C}_{0}<0.3 \mu \mathrm{g} / \mathrm{m}^{3}$, ELVOC: $\mathrm{C}_{0}<10^{-4}$ (Donahue et al., 2011; Li et al., 2016)) . 


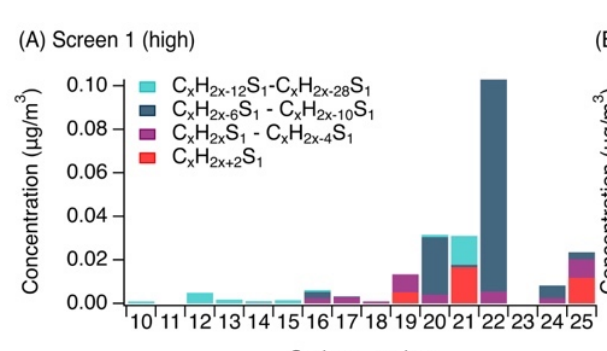

Carbon number



Carbon number
(B) Screen 2 (high)

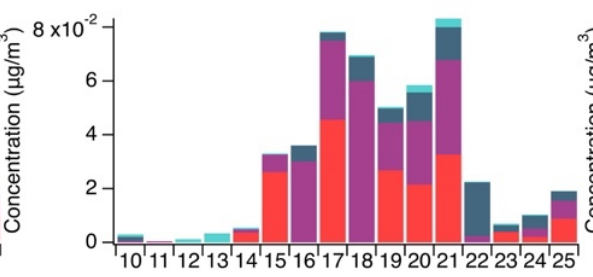

Carbon number

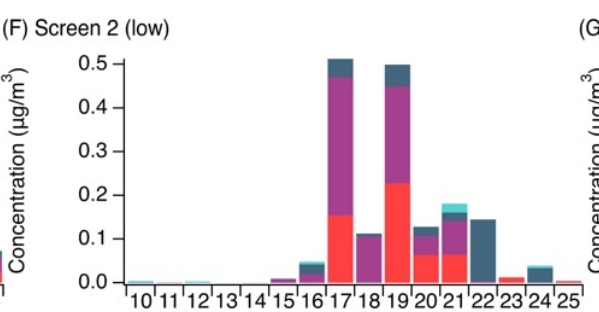

Carbon number



Carbon number

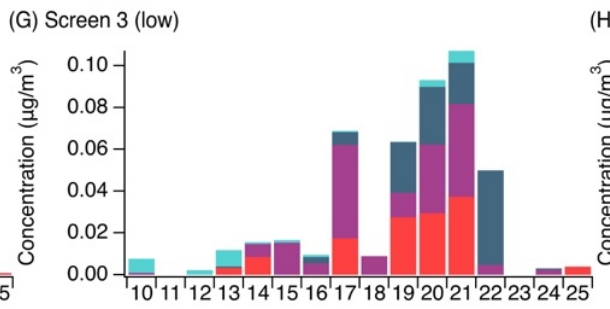

Carbon number
(D) Screen 4 (high)



Carbon number

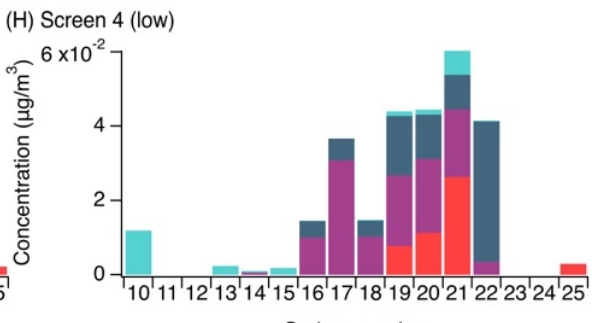

Figure S10. Distribution of carbon backbone structures for $\mathrm{C}_{\mathrm{x}} \mathrm{H}_{\mathrm{y}} \mathrm{S}_{1}$ compounds collected on adsorbent tubes across screens 1-4, from targeted GC-APCI-MS analysis. Here, $\mathrm{C}_{\mathrm{x}} \mathrm{H}_{2 \mathrm{x}+2} \mathrm{~S}_{1}$ represents saturated sulfur-containing compounds, $\mathrm{C}_{\mathrm{x}} \mathrm{H}_{2 \mathrm{x}} \mathrm{S}_{1}-\mathrm{C}_{\mathrm{x}} \mathrm{H}_{2 \mathrm{x}-4} \mathrm{~S}_{1}$ represents sulfur-containing compounds with the equivalent of 1-3 double bonds and/or rings, $\mathrm{C}_{\mathrm{x}} \mathrm{H}_{2 \mathrm{x}-6} \mathrm{~S}_{1}-\mathrm{C}_{\mathrm{x}} \mathrm{H}_{2 \mathrm{x}-10} \mathrm{~S}_{1}$ represents sulfur-containing compounds with the equivalent of 4-6 double bonds and/or rings (e.g. single-ring aromatics), and $\mathrm{C}_{\mathrm{x}} \mathrm{H}_{2 \mathrm{x}-12} \mathrm{~S}_{1}-\mathrm{C}_{\mathrm{x}} \mathrm{H}_{2 \mathrm{x}-28} \mathrm{~S}_{1}$ represents sulfur-containing compounds with the equivalent of 7-15 double bonds and/or rings (e.g. PAHs). Screen 1 (low altitude) and screens 2, 3, and 4 (high altitude) showed the highest acetonitrile concentration, suggesting that the corresponding adsorbent tube samples were collected from the most concentrated portions of the plume (when comparing each low/high altitude pair at each screen). Values on each y-axis were not normalized by carbon monoxide measurements, to show absolute concentration measured on each adsorbent tube. To account for dilution, concentrations were normalized by carbon monoxide (e.g. Figure 4B). Mixing ratios are shown in Table S1. 
(A) Distribution of gas-phase sulfur-containing compound structures

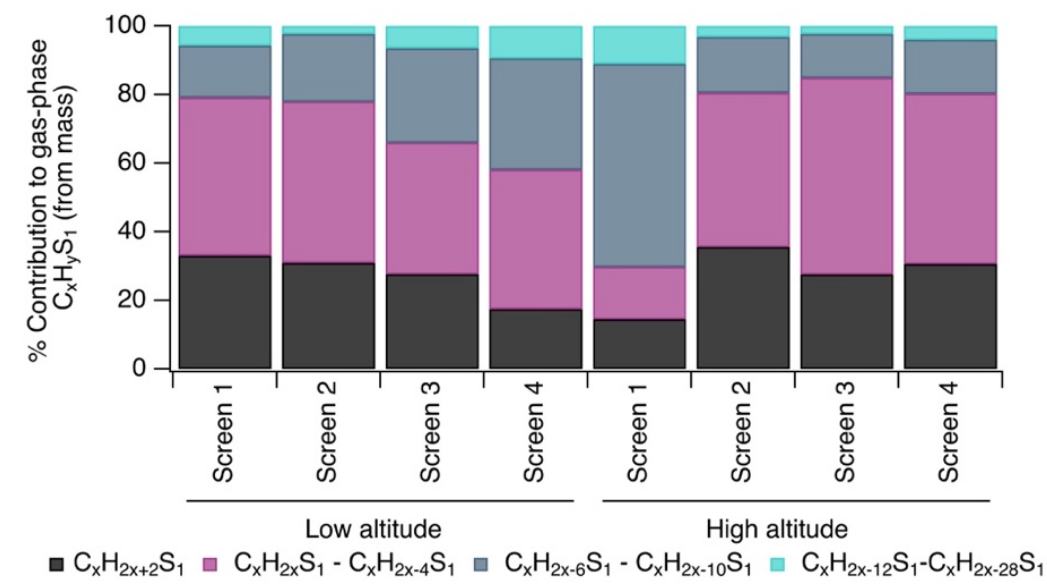

(B) Distribution of gas-phase nitrogen-containing compound structures

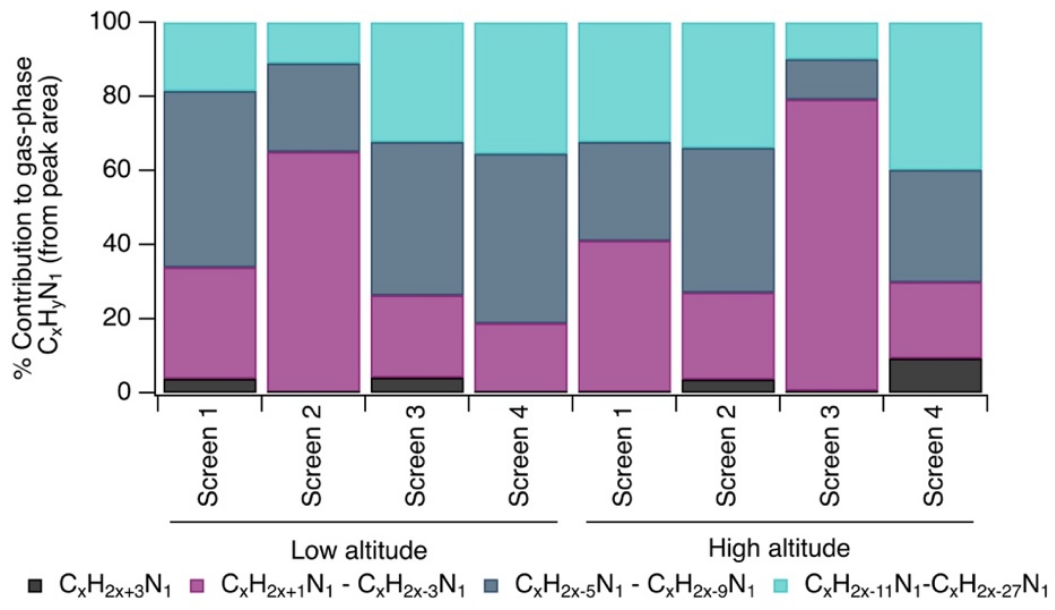

Figure S11. (A) Distribution of multiple bonds or ring structures for gas-phase $\mathrm{C}_{x} \mathrm{H}_{\mathrm{y}} \mathrm{S}_{1}$ compounds from targeted GC-APCI-MS analysis, where sulfur-containing compound peak areas were converted to mass as discussed in Section S3. (B) Distribution of multiple bonds or ring structures for gas-phase $\mathrm{C}_{\mathrm{x}} \mathrm{H}_{\mathrm{y}} \mathrm{N}_{1}$ compounds from targeted GC-APCI-MS analysis. The nitrogen distribution was based on peak area. This contained a range of nitriles, pyrroles, pyridines, and other structures similar to past work (Akagi et al., 2011; Andreae, 2019; Gilman et al., 2015; Hatch et al., 2015; Koss et al., 2018). For (A-B), sulfur and nitrogen can form single or multiple bonds, so the presence of multiple bonds or rings may be in the carbon backbone structure or on the sulfur/nitrogen heteroatom. Here, black bars represent saturated compounds, pink bars represent those with the equivalent of 1-3 double bonds and/or rings, dark teal bars represent those with the equivalent of 4-6 double bonds and/or rings (e.g. single ring aromatics), and light teal bars represent those with the equivalent of 7-15 double bonds and/or rings (e.g. PAHs). 
(A) Gas- and particle-phase concentrations by screen

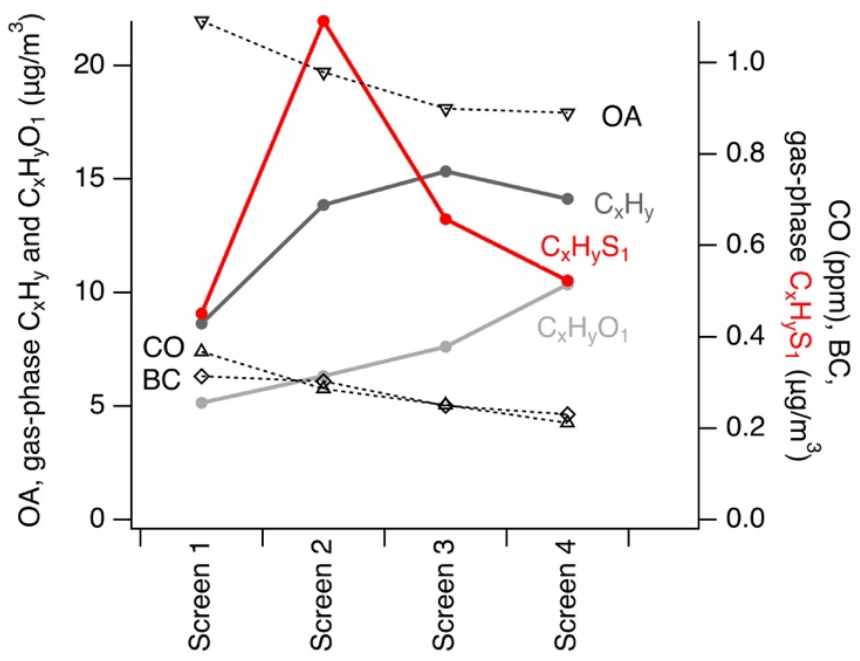

(B) Gas-phase distribution of compound classes

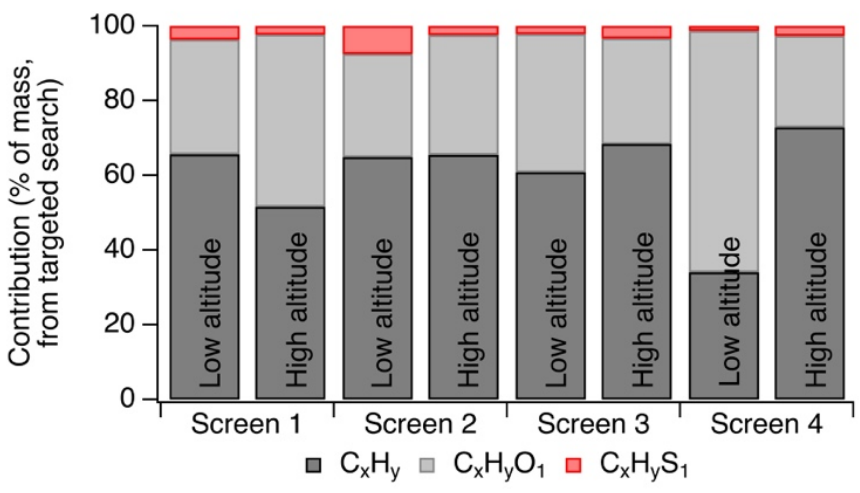

(C) PTR-MS correlations with acetonitrile emissions

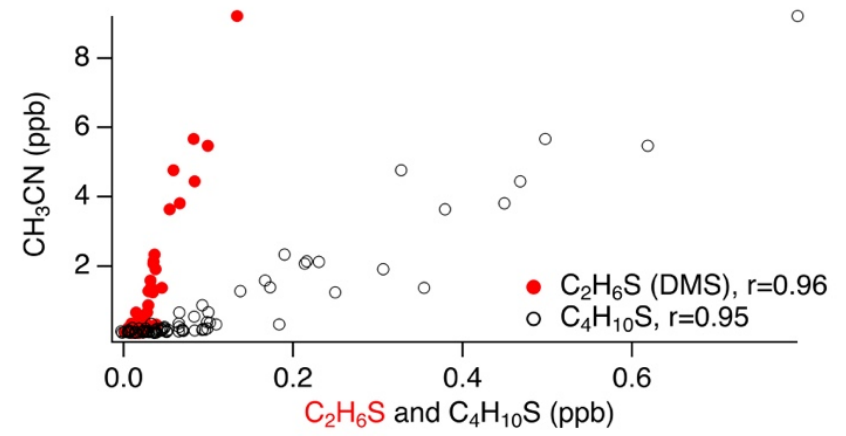

Figure S12. (A) Concentration of gas-phase $\mathrm{C}_{x} \mathrm{H}_{y}, \mathrm{C}_{x} \mathrm{H}_{y} \mathrm{O}_{1}$, and $\mathrm{C}_{\mathrm{x}} \mathrm{H}_{\mathrm{y}} \mathrm{S}_{1}$ compounds, $\mathrm{BC}$, OA from AMS, and $\mathrm{CO}$ as tracers of plume dilution (shown to support Figure 4B, concentrations not normalized by carbon monoxide here). (B) Relative contribution of $\mathrm{C}_{\mathrm{x}} \mathrm{H}_{\mathrm{y}}, \mathrm{C}_{\mathrm{x}} \mathrm{H}_{\mathrm{y}} \mathrm{O}_{1}$, and $\mathrm{C}_{\mathrm{x}} \mathrm{H}_{\mathrm{y}} \mathrm{S}_{1}$ compounds from the targeted search in the gas phase $\left(\mathrm{C}_{10}-\mathrm{C}_{25}\right)$ from GC-APCI-MS analysis. $\mathrm{C}_{\mathrm{x}} \mathrm{H}_{\mathrm{y}}, \mathrm{C}_{\mathrm{x}} \mathrm{H}_{\mathrm{y}} \mathrm{O}_{1}$, and $\mathrm{C}_{\mathrm{x}} \mathrm{H}_{\mathrm{y}} \mathrm{S}_{1}$ contributions were converted to mass concentrations prior to analysis. $\mathrm{C}_{\mathrm{x}} \mathrm{H}_{\mathrm{y}} \mathrm{N}_{1}$ was not included here because $\mathrm{C}_{\mathrm{x}} \mathrm{H}_{\mathrm{y}} \mathrm{N}_{1}$ was examined in terms of peak area only. (C) Correlation between concentration of $\mathrm{C}_{2} \mathrm{H}_{6} \mathrm{~S}$ (dimethylsulfide (DMS) and isomers) and $\mathrm{C}_{4} \mathrm{H}_{10} \mathrm{~S}$ (diethylsulfide and isomers) versus acetonitrile from aircraft PTR-ToF-MS data 




Carbon numbe

(E) Screen 1 (low)



Carbon number
(B) Screen 2 (high)



Carbon number
(C) Screen 3 (high)

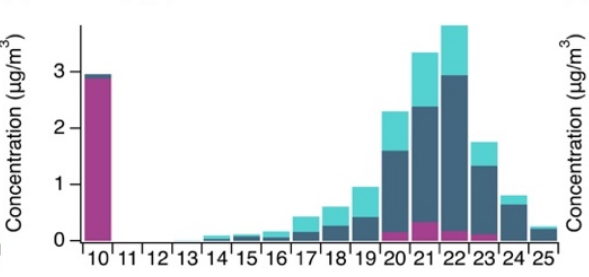

Carbon number
(D) Screen 4 (high)



Carbon number

(F) Screen 2 (low)

(G) Screen 3 (low)

(H) Screen 4 (low)



Carbon number

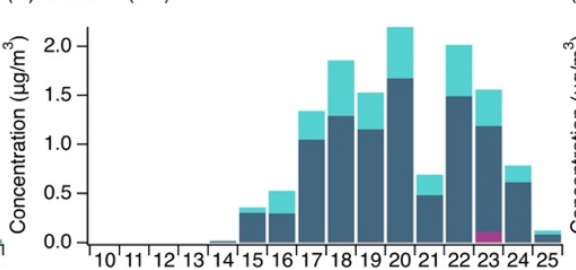

Carbon number

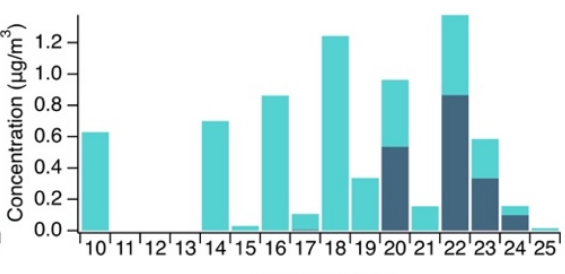

Carbon number

Figure S13. Distribution of carbon backbone structures for gas-phase $\mathrm{C}_{\mathrm{x}} \mathrm{H}_{\mathrm{y}}$ hydrocarbons collected on adsorbent tubes across screens 1-4 (from targeted GC-APCI-MS analysis). DBE 0-3 represents alkanes, alkenes, and cyclic alkanes. DBE 4-6 represents single ring aromatics. DBE 7-15 represents polycyclic aromatics hydrocarbons (PAHs). The observed $\mathrm{C}_{10}$ compounds classified as DBE 0-3 (pink) were dominated by monoterpenes. Screen 1 (low altitude) and screens 2, 3, and 4 (high altitude) showed the highest acetonitrile concentration, suggesting that the corresponding adsorbent tube samples were collected from the most concentrated portions of the plume. Values on each y-axis were not normalized by carbon monoxide measurements, to show absolute concentration measured on each adsorbent tube. To account for dilution, concentrations were normalized by carbon monoxide (e.g. Figure 4B). Mixing ratios are shown in Table S1. 
(1)

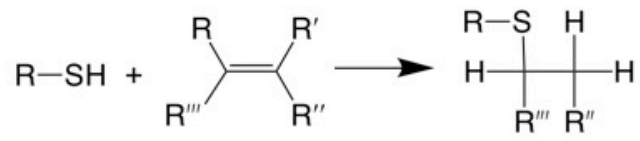

(2)

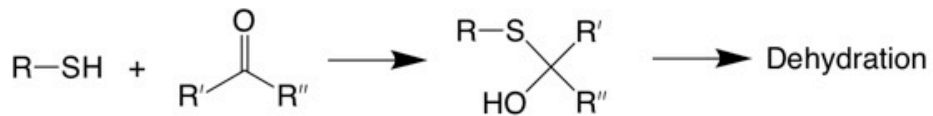

(3)

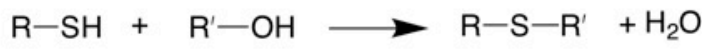

(4)

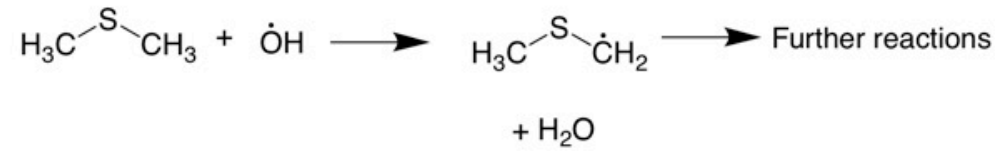

Figure S14. Possible reaction pathways from the literature, including (1) a thiol-ene reaction (Lowe, 2010), (2) reaction with a carbonyl (Jencks and Lienhard, 1966), (3) reaction with an alcohol (Mashkina, 1991), and (4) hydrogen abstraction from dimethyl sulfide (Barnes et al., 2006).

Table S1. Summary table of average flow rates, sampling times, and CO mixing ratios (ppm displayed here for ease of interpretation, but values in $\mu \mathrm{g} / \mathrm{m}^{3}$ were used to normalize ion abundances (counts $\left./ \mathrm{m}^{3}\right)$ or mass concentrations $\left(\mu \mathrm{g} / \mathrm{m}^{3}\right)$ ).

\begin{tabular}{|c|c|c|c|c|}
\hline \multicolumn{5}{|c|}{ Adsorbent tubes } \\
\hline Sample & $\begin{array}{c}\text { Average flow } \\
\text { rate (sccm) }\end{array}$ & $\begin{array}{c}\text { Sampling } \\
\text { time (min) }\end{array}$ & $\begin{array}{c}\text { Average } \\
\text { altitude (m) }\end{array}$ & $\begin{array}{c}\text { Average CO during } \\
\text { sampling (ppm) }\end{array}$ \\
\hline Screen 1, low altitude & 288 & 52 & 655 & 0.49 \\
Screen 2, low altitude & 276 & 7 & 641 & 0.15 \\
Screen 3, low altitude & 285 & 9 & 809 & 0.11 \\
Screen 4, low altitude & 291 & 4 & 727 & 0.18 \\
Screen 1, high altitude & 278 & 5 & 915 & 0.14 \\
Screen 2, high altitude & 280 & 44 & 1172 & 0.46 \\
Screen 3, high altitude & 282 & 47 & 962 & 0.39 \\
Screen 4, high altitude & 296 & 30 & 1645 & 0.28 \\
\hline \multicolumn{5}{|c|}{ Filters } \\
\hline Sample & Average flow & Sampling & Average & Average CO during \\
Screen 1 & rate (slpm) & time (min) & altitude (m) & sampling (ppm) \\
\hline Screen 2 & 47 & 52 & 1115 & 0.49 \\
Screen 3 & 46 & 44 & 1287 & 0.47 \\
Screen 4 & 46 & 47 & 1268 & 0.41 \\
Screen 5 & 47 & 29 & 932 & 0.30 \\
\hline
\end{tabular}


Table S2. Fraction of hydrocarbons from adsorbent tubes in the gas- vs. particle-phase, based on AMS OA concentration (18-22 $\mu \mathrm{g} / \mathrm{m}^{3}$, averaged across low and high altitude adsorbent tube sampling times) and the effective saturation concentration of hydrocarbons in the carbon number range of interest (Donahue et al., 2009, 2011).

\begin{tabular}{|c|c|c|c|c|}
\hline $\begin{array}{c}\mathbf{C}^{*} \\
\left(\mathbf{\mu g} / \mathbf{m}^{\mathbf{3}}\right)\end{array}$ & $\begin{array}{c}\mathbf{L o g}_{\mathbf{1 0}}\left(\mathbf{C}^{*}\right) \\
\left(\mathbf{\mu g} / \mathbf{m}^{\mathbf{3}}\right)\end{array}$ & $\begin{array}{c}\text { \# carbon } \\
\text { atoms }\end{array}$ & $\begin{array}{c}\text { Fraction in gas } \\
\text { phase }\end{array}$ & $\begin{array}{c}\text { Fraction in } \\
\text { particle phase }\end{array}$ \\
\hline 1000000 & 6.00 & 12.4 & 1.00 & 0.00 \\
100000 & 5.00 & 14.5 & 1.00 & 0.00 \\
10000 & 4.00 & 16.6 & 1.00 & 0.00 \\
1000 & 3.00 & 18.7 & 0.98 & 0.02 \\
100 & 2.00 & 20.8 & 0.84 & 0.16 \\
50 & 1.70 & 21.4 & 0.72 & 0.28 \\
30 & 1.48 & 21.9 & 0.61 & 0.39 \\
20 & 1.30 & 22.3 & 0.51 & 0.49 \\
10 & 1.00 & 22.9 & 0.34 & 0.66 \\
1 & 0.00 & 25.0 & 0.05 & 0.95 \\
\hline
\end{tabular}

Table S3. Comparison of AMS OA concentration and total targeted gas-phase $\mathrm{C}_{\mathrm{x}} \mathrm{H}_{\mathrm{y}}, \mathrm{C}_{\mathrm{x}} \mathrm{H}_{\mathrm{y}} \mathrm{O}_{1}$, $\mathrm{C}_{\mathrm{x}} \mathrm{H}_{\mathrm{y}} \mathrm{S}_{1}$ compound concentration, shown as a change between screens 1 and 2 . Columns show concentration difference and the ratio of targeted gas-phase compound concentration difference to carbon monoxide concentration difference.

\begin{tabular}{|l|c|c|}
\hline \multicolumn{1}{|c|}{ Screen $\mathbf{1 \rightarrow 2}$} & $\begin{array}{c}\text { Concentration } \\
\text { difference }\end{array}$ & $\begin{array}{c}\text { Ratio of concentration difference to } \\
\text { CO concentration difference }\end{array}$ \\
\hline AMS OA & $-2.3 \mu \mathrm{g} / \mathrm{m}^{3}$ & $-0.0044(7 \%$ decrease $)$ \\
\hline $\begin{array}{l}\Sigma\left(\mathrm{C}_{\mathrm{x}} \mathrm{H}_{\mathrm{y}}, \mathrm{C}_{\mathrm{x}} \mathrm{H}_{\mathrm{y}} \mathrm{O}_{1}, \mathrm{C}_{\mathrm{x}} \mathrm{H}_{\mathrm{y}} \mathrm{S}_{1}\right) \text { from } \\
\text { targeted adsorbent tube search }\end{array}$ & $+7.0 \mu \mathrm{g} / \mathrm{m}^{3}$ & $+0.022(55 \%$ increase $)$ \\
\hline
\end{tabular}




\section{References}

Akagi, S. K., Yokelson, R. J., Wiedinmyer, C., Alvarado, M. J., Reid, J. S., Karl, T., Crounse, J. D. and Wennberg, P. O.: Emission factors for open and domestic biomass burning for use in atmospheric models, Atmos. Chem. Phys., 11(9), 4039-4072, doi:10.5194/acp-114039-2011, 2011.

Andreae, M. O.: Emission of trace gases and aerosols from biomass burning - An updated assessment, Atmos. Chem. Phys., 1-27, doi:10.5194/acp-2019-303, 2019.

Barnes, I., Hjorth, J. and Mihalapoulos, N.: Dimethyl sulfide and dimethyl sulfoxide and their oxidation in the atmosphere, Chem. Rev., 106(3), 940-975, doi:10.1021/cr020529+, 2006.

Corrigan, A. L., Russell, L. M., Takahama, S., Äijälä, M., Ehn, M., Junninen, H., Rinne, J., Petäjä, T., Kulmala, M., Vogel, A. L., Hoffmann, T., Ebben, C. J., Geiger, F. M., Chhabra, P., Seinfeld, J. H., Worsnop, D. R., Song, W., Auld, J. and Williams, J.: Biogenic and biomass burning organic aerosol in a boreal forest at Hyytiälä, Finland, during HUMPPA-COPEC 2010, Atmos. Chem. Phys., 13(24), 12233-12256, doi:10.5194/acp-13-12233-2013, 2013.

Ditto, J. C., Barnes, E. B., Khare, P., Takeuchi, M., Joo, T., Bui, A. A. T., Lee-Taylor, J., Eris, G., Chen, Y., Aumont, B., Jimenez, J. L., Ng, N. L., Griffin, R. J. and Gentner, D. R.: An omnipresent diversity and variability in the chemical composition of atmospheric functionalized organic aerosol, Commun. Chem., 1(1), 75, doi:10.1038/s42004-0180074-3, 2018.

Ditto, J. C., Joo, T., Khare, P., Sheu, R., Takeuchi, M., Chen, Y., Xu, W., Bui, A. A. T., Sun, Y., Ng, N. L. and Gentner, D. R.: Effects of Molecular-Level Compositional Variability in 
Organic Aerosol on Phase State and Thermodynamic Mixing Behavior, Environ. Sci. Technol., 53(22), 13009-13018, doi:10.1021/acs.est.9b02664, 2019.

Ditto, J. C., Joo, T., Slade, J. H., Shepson, P. B., Ng, N. L. and Gentner, D. R.: Nontargeted Tandem Mass Spectrometry Analysis Reveals Diversity and Variability in Aerosol Functional Groups across Multiple Sites, Seasons, and Times of Day, Environ. Sci. Technol. Lett., 7(2), 60-69, doi:10.1021/acs.estlett.9b00702, 2020.

Donahue, N. M., Robinson, A. L. and Pandis, S. N.: Atmospheric organic particulate matter: From smoke to secondary organic aerosol, Atmos. Environ., 43(1), 94-106, doi:10.1016/j.atmosenv.2008.09.055, 2009.

Donahue, N. M., Epstein, S. A., Pandis, S. N. and Robinson, A. L.: A two-dimensional volatility basis set: 1. organic-aerosol mixing thermodynamics, Atmos. Chem. Phys., 11(7), 33033318, doi:10.5194/acp-11-3303-2011, 2011.

Gilman, J. B., Lerner, B. M., Kuster, W. C., Goldan, P. D., Warneke, C., Veres, P. R., Roberts, J. M., De Gouw, J. A., Burling, I. R. and Yokelson, R. J.: Biomass burning emissions and potential air quality impacts of volatile organic compounds and other trace gases from fuels common in the US, Atmos. Chem. Phys., 15(24), 13915-13938, doi:10.5194/acp15-13915-2015, 2015.

Hatch, L. E., Luo, W., Pankow, J. F., Yokelson, R. J., Stockwell, C. E. and Barsanti, K. C.: Identification and quantification of gaseous organic compounds emitted from biomass burning using two-dimensional gas chromatography-time-of-flight mass spectrometry, Atmos. Chem. Phys., 15(4), 1865-1899, doi:10.5194/acp-15-1865-2015, 2015.

Jencks, W. P. and Lienhard, G. E.: Thiol Addition to the Carbonyl Group. Equilibria and Kinetics, J. Am. Chem. Soc., 88(17), 3982-3995, doi:10.1021/ja00969a017, 1966. 
Khare, P., Marcotte, A., Sheu, R., Walsh, A. N., Ditto, J. C. and Gentner, D. R.: Advances in offline approaches for trace measurements of complex organic compound mixtures via soft ionization and high-resolution tandem mass spectrometry, J. Chromatogr. A, 1598, 163-174, doi:10.1016/j.chroma.2019.03.037, 2019.

Khare, P., Machesky, J., Soto, R., He, M., Presto, A. A. and Gentner, D. R.: Asphalt-related emissions are a major missing nontraditional source of secondary organic aerosol precursors, Sci. Adv., 6(36), doi:10.1126/sciadv.abb9785, 2020.

Kondyli, A. and Schrader, W.: Evaluation of the combination of different atmospheric pressure ionization sources for the analysis of extremely complex mixtures, Rapid Commun. Mass Spectrom., 34(8), 1-9, doi:10.1002/rcm.8676, 2019.

Koss, A. R., Sekimoto, K., Gilman, J. B., Selimovic, V., Coggon, M. M., Zarzana, K. J., Yuan, B., Lerner, B. M., Brown, S. S., Jimenez, J. L., Krechmer, J., Roberts, J. M., Warneke, C., Yokelson, R. J. and De Gouw, J.: Non-methane organic gas emissions from biomass burning: Identification, quantification, and emission factors from PTR-ToF during the FIREX 2016 laboratory experiment, Atmos. Chem. Phys., 18(5), 3299-3319, doi:10.5194/acp-18-3299-2018, 2018.

Kroll, J. H., Donahue, N. M., Jimenez, J. L., Kessler, S. H., Canagaratna, M. R., Wilson, K. R., Altieri, K. E., Mazzoleni, L. R., Wozniak, A. S., Bluhm, H., Mysak, E. R., Smith, J. D., Kolb, C. E. and Worsnop, D. R.: Carbon oxidation state as a metric for describing the chemistry of atmospheric organic aerosol., Nat. Chem., 3(2), 133-139, doi:10.1038/nchem.948, 2011.

Li, S. M., Leithead, A., Moussa, S. G., Liggio, J., Moran, M. D., Wang, D., Hayden, K., Darlington, A., Gordon, M., Staebler, R., Makar, P. A., Stroud, C. A., McLaren, R., Liu, 
P. S. K., O’Brien, J., Mittermeier, R. L., Zhang, J., Marson, G., Cober, S. G., Wolde, M. and Wentzell, J. J. B.: Differences between measured and reported volatile organic compound emissions from oil sands facilities in Alberta, Canada, Proc. Natl. Acad. Sci. U. S. A., 114(19), E3756-E3765, doi:10.1073/pnas.1617862114, 2017.

Li, Y., Pöschl, U. and Shiraiwa, M.: Molecular corridors and parameterizations of volatility in the chemical evolution of organic aerosols, Atmos. Chem. Phys., 16(5), 3327-3344, doi:10.5194/acp-16-3327-2016, 2016.

Lowe, A. B.: Thiol-ene "click" reactions and recent applications in polymer and materials synthesis, Polym. Chem., 1(1), 17-36, doi:10.1039/b9py00216b, 2010.

Mashkina, A. V.: Catalytic Synthesis Of Sulfides Sulfoxides and Sulfones, Sulfur reports, 10(4), 279-388, doi:10.1080/01961779108048759, 1991.

Middlebrook, A. M., Bahreini, R., Jimenez, J. L. and Canagaratna, M. R.: Evaluation of composition-dependent collection efficiencies for the Aerodyne aerosol mass spectrometer using field data, Aerosol Sci. Technol., 46(3), 258-271, doi:10.1080/02786826.2011.620041, 2012.

Ng, N. L., Kwan, A. J., Surratt, J. D., Chan, A. W. H., Chhabra, P. S., Sorooshian, A., Pye, H. O. T., Crounse, J. D., Wennberg, P. O., Flagan, R. C. and Seinfeld, J. H.: Secondary organic aerosol (SOA) formation from reaction of isoprene with nitrate radicals (NO3), Atmos. Chem. Phys., 8, 4117-4140, 2008.

Ochiai, N., Tsunokawa, J., Sasamoto, K. and Hoffmann, A.: Multi-volatile method for aroma analysis using sequential dynamic headspace sampling with an application to brewed coffee, J. Chromatogr. A, 1371, 65-73, doi:10.1016/j.chroma.2014.10.074, 2014.

Riva, M., Da Silva Barbosa, T., Lin, Y.-H., Stone, E. A., Gold, A., Surratt, J. D., Barbosa, T. D. 
S., Lin, Y.-H., Stone, E. A. and Gold, A.: Characterization of organosulfates in secondary organic aerosol derived from the photooxidation of long-chain alkanes, Atmos. Chem. Phys., 16, 11001-11018, doi:10.5194/acp-2016-20, 2016a.

Riva, M., Budisulistiorini, S. H., Chen, Y., Zhang, Z., D’Ambro, E. L., Zhang, X., Gold, A., Turpin, B. J., Thornton, J. A., Canagaratna, M. R. and Surratt, J. D.: Chemical Characterization of Secondary Organic Aerosol from Oxidation of Isoprene Hydroxyhydroperoxides, Environ. Sci. Technol., 50, 9889-9899, doi:10.1021/acs.est.6b02511, 2016b.

Schauer, J. J., Kleeman, M. J., Cass, G. R. and Simoneit, B. R. T.: Measurement of emissions from air pollution sources. 3. C1-C29 organic compounds from fireplace combustion of wood, Environ. Sci. Technol., 35(9), 1716-1728, doi:10.1021/es001331e, 2001.

Seinfeld, J. H., Surratt, J. D., Gomez-Gonzalez, Y., Chan, A. W. H., Vermeylen, R., Shahgholi, M., Kleindienst, T. E., Edney, E. O., Offenberg, J. H., Lewandowski, M., Jaoui, M., Maenhaut, W., Claeys, M., Flagan, R. C. and Seinfeld, J. H.: Organosulfate Formation in Biogenic Secondary Organic Aerosol, J. Phys. Chem. A, 112(36), 8345-8378, doi:Doi 10.1021/Jp802310p, 2008.

Sheu, R., Marcotte, A., Khare, P., Charan, S., Ditto, J. C. and Gentner, D. R.: Advances in offline approaches for chemically speciated measurements of trace gas-phase organic compounds via adsorbent tubes in an integrated sampling-to-analysis system, J. Chromatogr. A, 1575, 80-90, doi:10.1016/j.chroma.2018.09.014, 2018.

Simoneit, B. R. T., Rogge, W. F., Mazurek, M. A., Standley, L. J., Hildemann, L. M. and Cass, G. R.: Lignin Pyrolysis Products, Lignans, and Resin Acids as Specific Tracers of Plant Classes in Emissions from Biomass Combustion, Environ. Sci. Technol., 27(12), 2533- 
2541, doi:10.1021/es00048a034, 1993.

Worton, D. R., Zhang, H., Isaacman-Vanwertz, G., Chan, A. W. H. H., Wilson, K. R. and Goldstein, A. H.: Comprehensive Chemical Characterization of Hydrocarbons in NIST Standard Reference Material 2779 Gulf of Mexico Crude Oil, Environ. Sci. Technol., 49(22), 13130-13138, doi:10.1021/acs.est.5b03472, 2015.

Zhou, S., Collier, S., Jaffe, D. A., Briggs, N. L., Hee, J., Iii, A. J. S., Kleinman, L., Onasch, T. B. and Zhang, Q.: Regional influence of wildfires on aerosol chemistry in the western US and insights into atmospheric aging of biomass burning organic aerosol, Atmos. Chem. Phys., 17(3), 2477-2493, doi:10.5194/acp-17-2477-2017, 2017. 